\title{
Smile Theory of Everything
}

\author{
Satish Gajawada \\ The Human, Passport number (INDIA): H3396517 \\ Hyderabad, Andhra Pradesh, INDIA, Planet EARTH.
}

\begin{abstract}
I would like to thank everything in this universe which is trying to make this place a better place to live. This report is all about "Smile Theory of Everything (SToE)". In this theory the same thing is given in different formats.
\end{abstract}

Keywords: Smile, Religion, GOD, Everything, Human, Earth, Hurrah

\section{Introduction}

There are many ways in which one can bring smile on the face of others. A human can imagine the feel of bringing smile on others face simply by looking his own smile with the help of a mirror. Summer season may be very hot but some methods may be used for smile creation. These methods can bring coolness and interest even during summer season. Smile creation is a wonderful field of research. The beauty of this smile creation field is that smile is the final result that one wants no matter what someone does i.e., whether we do "bits, bytes and protocols" or "profits, losses and margins" ultimately it is to smile and make others smile. Smile computing or new religion or unified theory is introduced in this paper in an attempt to pass the experience of the corresponding author for making this earth a better place to live.

Section 2 gives Truth which is first format. Some methods for smile creation is 2nd format shown in third section. Smiles discovered or created during summer 2011 are described in Section 4. Application of Smile computing method during a festival is explained in fifth section. Section 6 shows methods I used for getting happiness and satisfaction during a birthday. Final part shows photography art based method or figure taken by author which is the final format shown in this work for smile creation in this high dimensional world.

\section{TRUTH}

Hare God Hare Hare, Allah Allah Hare Hare. Hare Buddha Hare Hare. Rama Rama Hare Hare. Krishna Krishna Hare Hare. Hare Human Hare Hare. Hare Jesus Hare Hare. Professor Professor Hare Hare. Friend Friend Hare Hare. Parents Parents Hare Hare. Philosophy Hare Hare. Religion Hare Hare. Computer Science Hare Hare, Every Department Hare Hare. Others Others Hare Hare. Every One Hare Hare. Hare Everything Hare Hare. Universe Universe Hare Hare.

\section{Some Methods For Smile Creation}

When your friend asks "Do you have good movies?" and you instead of saying No think of another friend who collects good movies and go to that friend as if you want to see movies and ask that friend who has movies "Please give me your hard disk to copy movies" and he may say NO and then you convince him that it will generate lot of happiness for another friend and request him for 5 minutes and finally he will give them and take those and give them to friend who asked you and believe in me he will smile and say thank you and you will feel like swimming(not just flying) in the sky :-)

Your friend may go out of station and suddenly he needs something urgent to be done by you which he cannot do it from there and so you decide to go out but then it may be very hot outside and you may feel like saying sorry I can't do it to your friend. Then somehow make your brain sleep and without any thinking just go and no matter how difficult it is complete the task and call your friend and say that you have done it and he will say Thank you! Thank you! and you will feel like Yahoo! :-

May be you have struggled hard for 6 months and gathered material and stored in a secret place so that no one can get it and I think if your goal is solving problem then sharing that material may help friend get an idea and solve it and may be if you don't share and hide it who knows that problem will remain as problem and so it is difficult but if possible just mail to your group some important thing if your goal is to solve a problem and you don't matter whether problem is solved by your friend or you and your focus is just to solve the problem and you sharing important things may trigger solving of that problem by your friend $(:)$

When you go to market and your hands are not full then call your friend whether he wants anything because otherwise he should also come to market to buy that thing and your help surely makes him feel that you are there for him $:$

Your friend may come to your room and say I got admission into best college for higher studies and then what you do just say yes! and dance with him and do whatever you do if you get admission into that 
college (imagine and then do) because you are $\mathrm{x}$ and your friend is $\mathrm{y}$ and you both together must make total i.e. $\mathrm{x}+\mathrm{y}=1$ and $(0+1)$ and $(1+0)$ equals total 1 and if you haven't understood what I said then in simple words whether you gets admission or your friend gets admission it is equivalent because there is a problem and you both together must solve it and it doesn't matter whether you solve it or your friend solves it because it is total which is important and not individual value. So your friend getting admission is equivalent to you getting admission and hence smile on his face $:-$

When you go out and you see a person trying to sell balloons but no one is buying then just buy two or three and atleast because of you some balloons will be sold and give that balloons as gift to friends and make them happy. This one act generates happiness at more than one place i.e. your friend and that person selling balloons and you all are happy $: ;$

There will be many beautiful things that occur in day-to-day life like person returning extra money you gave by chance at canteen instead of keeping it with him and not telling you and a child working nearby saying hello and giving a big smile and your friend fighting for solving problem with great heart and all these things are wonderful and don't forget to share them as it creates a positive impact $(:)$

There are sites like www.helpothers.org where people post wonderful stories after they do good things and your appreciation for their post makes their day beautiful and who knows it may trigger another kind action by them (-)

When you took your friends umbrella and by chance you exchanged it to very old umbrella at some other place then there is wonderful idea to create smile on your friends face. Because you don't have umbrella it is sure that you will buy one and so instead of giving your friend a old umbrella which is by chance exchanged at someother place and tell him sorry, your umbrella was exchanged just give the new umbrella to him and keep the old one for you and then you will feel like rocking this life :-;

\section{WOW! SUMMER 2011!}

One day when you are cleaning your room with water...it may happen that two ants are stuck between water and you may see that and your brain may say "let them die who cares" and just ignore it and take a paper and keep it near ants which are in between water and then two ants climb the paper and believe in me you have saved their life! Hurrah!

One day you may sit in class and your professor may ask "why don't you give a voluntary presentation on this topic?" Then your brain may say "there are no marks! There are no marks! for this and don't say yes " and your heart may say "It is a rare chance to make whole class smile for around 15 minutes" and then you kick the brain and give chance to heart and say "Yes! I will give a voluntary presentation" and later prepare it in such a way that you can make people smile and go and give presentation for free and when you see people laughing and your inner voice says Yes! Yes!

You may have studied a course and you have that textbook and you don't need it anymore and one of your friend needs it. Maybe he never asked the book but call him and ask "do you need this book?" and he says yes and you just go to his room as if you want the book from him and just give him the book and come back and while coming back don't forget to watch the wonderful smile on his face! Awesome!

One day you may be walking from room to mess and in between a person may ask "Do you have any unwanted papers? I will buy it". You just go to your room and find all the papers and you may have some unwanted books and while coming back another person may ask "are you giving these papers away for person standing outside? Can I take them?" and then you give half papers to him and remaining papers to person standing outside. Don't take money from them because it is not a big deal for you. Wow! you created two smiles (:) :)

One day it may happen that results are declared and your friend is failed and he has to go out from college and then you just go to computer centre and then find some inspirational quote or something and then print on a paper and stick it on thick paper and cut it in proper shape and you give it to him. It is not a big deal whether you go for parties with him or not but when he is in trouble you must be there with him or atleast try something for making him feel good. Yeah it is difficult as first you must go to computer centre and search for few hours and then you must go out and print and cut and then giving... doing this is difficult but not doing this is much more difficult if he is really your friend!

Maybe you have come across some post and some great heart wants to clear the confusion and you know the answer and then just reply to post as if your best friend is in trouble and clear confusion because it may have big effect on the other side $(;)$ Wow $: ;$

Maybe your friend is in trouble and asks you to come for a walk for an hour and this is the moment you must be there with him and listen to him and go for walk with him and for sometime slap the brain and kick it off if it sends signals like "me me me.." to you and listen to heart which says "help him help him" and this is one of the wonderful kindness acts you have done :)

You may create account in www.helpothers.org website and join the kindness group where you can find many ways how people across the globe are making this world a better place to live. 


\section{Festival Based Algorithm For Smile Creation}

There are many ways to implement this algorithm and the following implementation was tried. Step 1: Found a wonderful colourful shirt in the room.

Step 2: Realized I just wear T-shirts all the time and giving away this colourful shirt doesn't make much damage. Step 3: Found a worker who is good and sincere and also observed that one colourful shirt can make his holi colourful.

Step 4: Brain will send signals "Are you giving this shirt to him. Are you gone mad?" and it will give 1000 reasons not to give that shirt to worker.

Step 5: Slap the Brain and give the control to heart and give 100000 reasons why you want to give the shirt to worker.

Step 6: This is the mind blowing step where you give the shirt and you will find a big smile on the face on worker and also he will say "Thank you" and you will feel like swimming (not just flying) in the sky.

\section{Birthday Based Method For Optimal Smile Creation}

On Birthdays we may spend thousands and sometimes lakhs in some cases. What I did on my birthday based method is I changed few parameter values. Generally self parameter is more and others in need parameter is less. What I did is I tried to decrease self by some amount and increase others in need and distributed money to others in need also. I found many smiles and that created smile on my face. This overall thing may be termed as "Smile Effect" where each human created smile on the face of other humans. I am unable to express happiness because somethings in life cannot be expressed or published but they can only be felt.

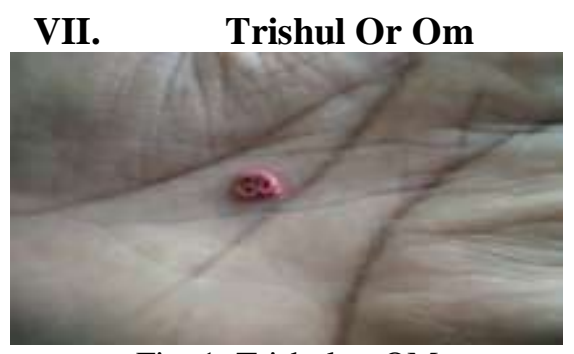

Fig. 1: Trishul or OM

\section{Acknowledgements}

I would like to thank everything on this planet which is trying to make this place a better place to live.

\section{Conclusion}

In this paper a new religion or unified theory titled "Smile computing" is introduced. I can't write here with words because not everything in life can be expressed with words because somethings in life can only be felt with heart. There are many ways to create smiles if you really want to do it. It is beautiful when someone smiles and even more beautiful thing is to know that you are the reason behind it. Summers may be cool and interesting! There is much more but not everything in life can be expressed with numbers like "number of marks obtained", "number of dollars earned", "number of times blah blah.." etc because somethings in life can only be felt with heart:- Wow! Hurrah! Aweseome! Mind Blowing! Great! Cool!@ I will just say the reason "I am wearing that colourful shirt and some friend because of holi bought colours and made that shirt even more colourful with colours and that shirt is no more useful". This is a small lie. Actually that incident has not happened. Wow! the worker felt really happy after I gave him colourful shirt. You have to try this method on your birthday and many smiles are created by this method. I am unable to express happiness as ENGLISH language is not sufficient to express all the things that happen in life. Also it is observed that BRAIN may give optimal solution as "self $=1$ " and "others $=0$ " and it proves it to be correct. Be careful with this BRAIN. Sometimes give the control to HEART so that you may get results which otherwise are impossible. Finally, in future if you come across miracles that cannot be explained in science then it's ok because this is high dimensional world. EYE wrote this paper and you find some way to pass your experience or miracle so that this world turns into much better form. 